\title{
Coral Communities, in Contrast to Fish Communities, Maintain a High Assembly Similarity along the Large Latitudinal Gradient along the Saudi Red Sea Coast
}

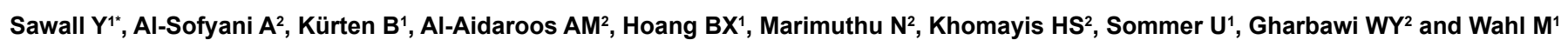

${ }^{1}$ Helmholtz Center for Ocean Research (GEOMAR), Experimental Ecology group, Duesternbrookerweg 20, 24105 Kiel, Germany

${ }^{2}$ Faculty of Marine Science, Department of Marine Biology, King Abdulaziz University, Post Box No. 80207, Jeddah- 21589, Saudi Arabia

\begin{abstract}
The Saudi Arabian Red Sea coast is characterized by a strong environmental gradient from north $\left(28.5^{\circ} \mathrm{N}\right)$ to south $\left(16.5^{\circ} \mathrm{N}\right)$ with challenging conditions for coral growth particularly in the south (high temperature and nutrient input). We investigated whether assemblies of reef-building corals and the distribution of functional groups follow a latitudinal pattern in the Red Sea, and whether these changes affect the assembly structure of coral associated organisms (e.g. fishes). Functional groups were defined based on life-history traits and functional role. 13 reefs along the north-south gradient, including 5 potentially polluted reefs were investigated. Results showed a substantially weaker latitudinal shift in the assembly structure of coral communities than of fishes communities and of other benthic reef taxa. Competitive fast growing branching and tabular species (mainly Acropora), as well as rather stresstolerant slow growing bulky species (e.g. Porites, Goniastrea, Favites, Favia) were fairly evenly distributed along the north-south axis despite strong changes of environmental conditions. This seems on the one hand attributable to the high species richness within a given functional group (functional redundancy) and on the other hand to a high acclimatization / adaptation potential of some Red Sea coral species. The prime ecosystem service of the coral community, the provision of a habitat complex, is thereby maintained throughout the gradient. In contrast to the coral community, the assembly of the fish community shifts along the environmental gradient with higher abundances of small wrasses and butterfly fishes in the north, and overall higher abundance of fishes including large fishes in the south. This shift seems linked to higher food availability in the south. Altered assembly structures of coral communities were found in reefs close to a source of pollution with either an increased relative abundance of stresstolerant species or a general decrease of coral abundance, latter case accompanied by a substantial reduction in fish abundance.
\end{abstract}

Keywords: Red Sea; Reef community assembly; Functional groups; Latitudinal gradient; Pollution

\section{Introduction}

TheRedSeaisauniquehabitat characterized byseveralenvironmental conditions considered potentially stressful for coral reef growth [1]. Those occur particularly in the south, where high temperatures (up to $33^{\circ} \mathrm{C}$ ) and high nutrient inputs (leading to chlorophyll $a$ concentration up to $4.0 \mu \mathrm{g} \mathrm{l}^{-1}$ ) co-occur. In contrast, the northern Red Sea is largely oligotrophic (Figure. 1A); [2,3] and temperatures remain below $30^{\circ} \mathrm{C}[4]$. The most northern region, the Gulf of Aqaba, features the lowest regional temperatures $\left(21-27^{\circ} \mathrm{C}\right)$, highest salinity $(<42 \mathrm{PSU})$ and low chlorophyll concentrations $\left(0.1-0.4 \mu \mathrm{g} \mathrm{chl} \mathrm{a} \mathrm{l}^{-1}\right.$, Figure $\left.1 \mathrm{~A}\right)$. Although, the Red Sea is at the most northwestern end of the tropical Indo-Pacific, coral diversity is high (>260 hermatypic coral species) and reef communities are complex throughout the Red Sea [5]. While a thorough study on coral community structure and diversity patterns in 1991 identified a clear zonation into a northern, central and southern Red Sea region a [6] recent study on coral communities suggested an increase in community homogenization within the last two decades throughout the Red Sea [7]. This was inter alia related to environmental changes such as ocean warming [7], which affects some species more than others [8], leading to a decimation of some species and a spread of other pecies [7]. However, it remains to be assessed whether changes in coral abundance and diversity patterns in the Red Sea alter the reef functionality and whether differences in the functionality (ecological role) exist along the latitudinal gradient.

Hermatypic corals are the main bioengineers of coral reefs creating a structurally complex habitat for various reef associated organisms. For example, structural complexity was found to strongly favor fish abundance. Structural complexity is particularly high when the abundance of branching corals is high [9]. Many branching corals belong to the genus Acropora, which are competitvely favored due to their rapid growth, but rather sensitive to stress [10]. Potentially stressful conditions (e.g. high turbidity, high temperature or temperature fluctuations, pollutants) could lead to a community shift towards more stress-tolerant species, which are generally represented by rather bulky and slow growing corals such as most Porites, Goniastrea, Favites, Favia and Lobophyllia [10], entailing inter alia a lower structural complexity [9]. A decreased abundance of herbivore fishes may lead to proliferation of macroalgae, in particular when nutrient levels are increased, which in return lowers coral recruitment success $[11,12]$. When a functional group is composed by several species, this redundancy may render a given function, for example provision of structure, as well as a higher resilience to disturbances and stress [9,13-15]. Therefore, it is important to assess not only coral species diversity, but also the functional

*Corresponding author: Sawall Y, Helmholtz Center for Ocean Research (GEOMAR), Experimental Ecology group, Duesternbrookerweg 20, $24105 \mathrm{Kiel}$, Germany, Tel: +49 (0)4316004577; E mail: ysawall@geomar.de

Received September 27, 2013; Accepted November 28, 2013; Published February 14, 2014

Citation: Sawall Y, Al-Sofyani A, Kürten B, Al-Aidaroos AM, Hoang BX, et al (2014) Coral Communities, in Contrast to Fish Communities, Maintain a High Assembly Similarity along the Large Latitudinal Gradient along the Saudi Red Sea Coast. J Ecosys Ecograph S4: 003. doi: 10.4172/2157-7625.S4-003

Copyright: ( 2014 Sawall Y, et al. This is an open-access article distributed under the terms of the Creative Commons Attribution License, which permits unrestricted use, distribution, and reproduction in any medium, provided the original author and source are credited. 
Citation: Sawall Y, Al-Sofyani A, Kürten B, Al-Aidaroos AM, Hoang BX, et al. (2014) Coral Communities, in Contrast to Fish Communities, Maintain a High Assembly Similarity along the Large Latitudinal Gradient along the Saudi Red Sea Coast. J Ecosys Ecograph S4: 003. doi: 10.4172/2157-7625.S4-003

Page 2 of 7

components of coral reef communities (corals, fishes, non-coral benthic invertebrates) in order to evaluate the resilience of ecosystem services to disturbances and stress. Such an assessment along the latitudinal gradient of the Red Sea is of particular interest in the light of predicted global change scenarios, since reefs in the southern Red Sea already persist under conditions predicted for other geographic regions in the future (sea surface temperatures $>31^{\circ} \mathrm{C}$, ICPP 2007 is reference number 37; high nutrient input) [16]. Thus, the assessment of coral reef functionality, particularly in the southern Red Sea, may provide a "preview" of potential future scenarios for reefs in the northern-central region of the Red Sea and for other geographic regions.

In this study, we assessed a) coral assemblies based on functional groups reflecting their life-history traits and growth forms, b) fish assemblies based on functional groups reflecting feeding mode and size, and c) the abundance of selected benthic indicator species. This was conducted at off-shore reefs along the nautral latitudinal environmental gradient, as well as at near-shore reefs close to sources of pollution. The results are discussed in the context of environmental changes.

\section{Material and Methods}

Thirteen reefs were investigated along the Saudi Arabian Red Sea coast between $16^{\circ} 34^{\prime}$ and $28^{\circ} 31^{\prime} \mathrm{N}$ in a total of 7 regions (Figure 1). In 5 regions, not only reefs far away from any source of pollution appearing unaffected and healthy, but also reefs close to a potential source of pollution were selected (Figure 1). The study sites were consecutively numbered from north to south (1 to 7) and denoted with "N" for nonpolluted and " $\mathrm{P}$ " for polluted in superscript throughout the manuscript. The sources of pollution were within $500 \mathrm{~m}$ of the impacted sites
A)

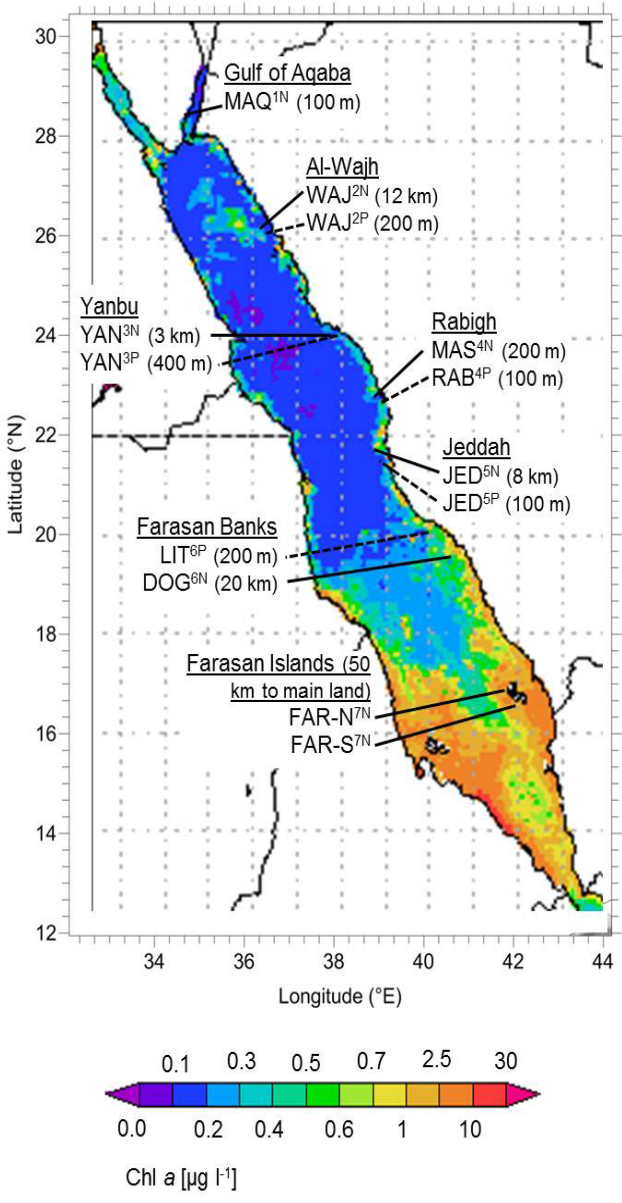

B)

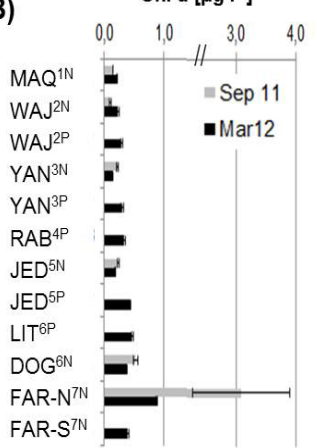

Total $\mathbf{N}[\mu \mathrm{M}]$

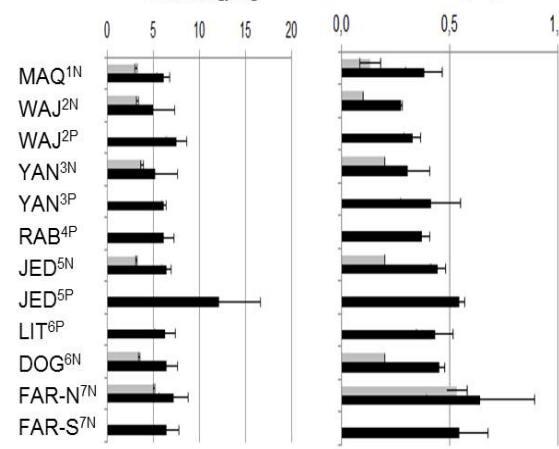

C)

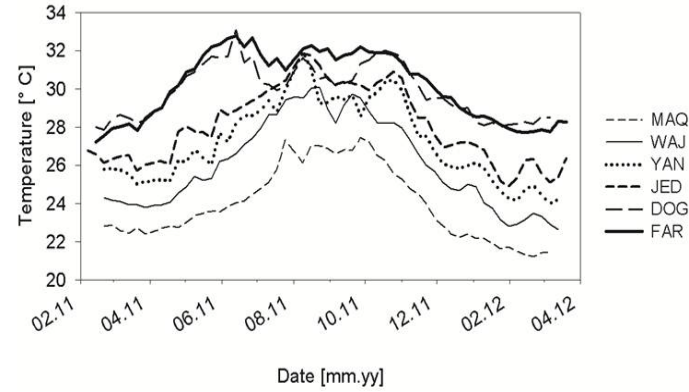

Figure 1: Study sites and environmental conditions. A) Map of the Red Sea representing the mean annual chlorophyll a (chl a) concentrations from April 2011 to March 2012 and the study sites. Regions (underlined), non-polluted sites (connected with a black line) and sites close to a source of pollution (connected with a dotted line). Distance to shore is given in brackets. Chl a data derived from satellite images of NASA, Giovanni online data system, Ocean Color Radiometry, data set: MODIS-Aqua

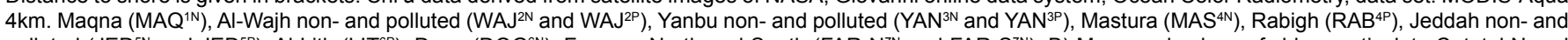
polluted (JED ${ }^{5 \mathrm{~N}}$ and JED $\left.{ }^{5 \mathrm{P}}\right)$, Al-Lith (LIT $\left.{ }^{6 \mathrm{P}}\right)$, Doga $\left(\mathrm{DOG}^{6 \mathrm{~N}}\right)$, Farasan North and South (FAR-N ${ }^{7 \mathrm{~N}}$ and FAR-S ${ }^{7 \mathrm{~N}}$ ). B) Measured values of chl a, particulate C, total N and total $\mathrm{P}$ from $\mathrm{N}$ to S. C) Measured temperature trends in $3 \mathrm{~m}$ depth at the non-polluted sites from February 2011 until March 2012. 
Citation: Sawall Y, Al-Sofyani A, Kürten B, Al-Aidaroos AM, Hoang BX, et al. (2014) Coral Communities, in Contrast to Fish Communities, Maintain a High Assembly Similarity along the Large Latitudinal Gradient along the Saudi Red Sea Coast. J Ecosys Ecograph S4: 003. doi: 10.4172/2157-7625.S4-003

Page 3 of 7

and varied by type: WAJ ${ }^{2 \mathrm{P}}$ was close to a desalination plant in front of the town Al-Wajh, YAN ${ }^{3 P}$ was close to a petro-chemicals factory and construction site in Yanbu, $\mathrm{RAB}^{4 \mathrm{P}}$ was close to a cement factory, oil refinery and power plant in Rabigh, JED ${ }^{5 \mathrm{P}}$ was in proximity of a domestic waste water discharge of the major city Jeddah, and LIT $^{6 \mathrm{P}}$ was close to the aquacultural waste water discharge of a large shrimp farm in Al-Lith. Regrettably, no data quantifying the anthropogenic impact at these sites were accessible. Fishing pressure is comparatively low in the Saudi Arabian waters of the Red Sea [17], but may be increased locally for example at the Farasan Islands, Farasan Banks and off AlWajh, where mainly edible fish is captured, but also fish for aquarium trade and sea cucumbers [17].

All selected sites were facing towards the exposed seaward side and a 100-m-long transects was laid out in 3-4 m depth along the reef crest (most sites) or perpendicular to a shallow slope (LIT ${ }^{6 \mathrm{P}}$ and FAR$\mathrm{S}^{7 \mathrm{~N}}$ ) in March 2012. Coral composition and abundances were recorded along the transects and assigned to one of the 12 pre-defined functional taxa reflecting the major life-history traits growth form, growth speed and susceptibility to bleaching/stress (Table 1) [18]. The different coral taxa were further assigned to one of the three overarching strategic groups defined by Darling [10,19] with a competitive group including fast growing broadcast spawning species, b) a weedy group including mainly brooding species with a short generation time and small colony size and c) a stress-tolerant group including slow growing broadcast spawning species with a high fecundity (presented by different colors in Table 1). Furthermore, soft corals, fleshy macroalgae and other sessile organisms (e.g. tunicates, bryozoans, anemones, sponges) as well as rock, coral rubble, sand and silt were quantified (Table 1). Along the same transect, in a belt of $4 \mathrm{~m}$ width, we quantified benthic invertebrates

\begin{tabular}{|c|c|c|c|c|}
\hline $\begin{array}{l}\text { Taxon / functional } \\
\text { group }\end{array}$ & Growth form / structural complexity & Growth speed & $\begin{array}{c}\text { Susceptability to } \\
\text { bleaching* }\end{array}$ & Example species \\
\hline 1: Acropora & bushy: short thick branches / moderate & moderate & medium & A. gemmifera, A. humilis \\
\hline 2: Acropora & long branches / high & fast & medium & A. intermedia, A. formosa, \\
\hline 3: Acroporidae & table like / high & fast & low - medium & A. lamarcki, A. cytherea \\
\hline 4: Pocillopora & bushy: short thick branches / moderate & moderate & low - medium & P. verrucosa, $P$. damicornis \\
\hline 5: Stylophora & bushy: short thick branches / moderate & moderate & medium & S. pistillata, S. wellsi \\
\hline 6: Millepora & branching or wall-like / moderate & fast & high & M. dichotoma \\
\hline 7: Poritidae & massive or finger-like / low - moderate & slow & low - medium & P. lutea, P. columnaris, Goniopora spp. \\
\hline 8: Faviidae & massive or encrusting / low & slow & low - medium & $\begin{array}{c}\text { Leptastrea purpurea, Favia stelligera, Goniastrea } \\
\text { retiformis, Platygyra spp. }\end{array}$ \\
\hline 9: Musiidae & massive / low & slow & medium & Lobophyllia corymbosa, Acanthastrea echinata \\
\hline 10: Oculinidae & massive / low & slow & low - medium & Galaxea fascicularis \\
\hline 11: Acroporidae & encrusting / low & moderate & low - medium & Montipora monasteriata \\
\hline 12: Other corals & diverse & diverse & diverse & Pavona, Coscinarae, Distichopora, Seriatopora \\
\hline 13: Soft corals & carpet-like, low branches / low & fast (usually) & low - medium & Xenia, Sinulari, Sarcophyton \\
\hline 14: Macro algae & carpet-like, low bushes, blades / low-mod. & very fast & - & Halimeda, Dictyosphaeria, Caulerpa, Turbinaria \\
\hline 15: Other sessile org. & diverse filter feeders & diverse & - & Tunicates, bryozoans, sponges, anemones \\
\hline 16: Rock & - / moderate & & & (dead coral boulders and rock) \\
\hline 17: Rubble & - / low (moving substrate) & & & (small dead coral pieces max. 15 cm long) \\
\hline 18: Sand & $-1-$ & & & \\
\hline 19: Silt & $-1-$ & & & \\
\hline
\end{tabular}

Table 1: Functional groups of hermatypic corals, other sessile organisms and non-living substrate, grouping based on growth form, growth speed and susceptibility to bleaching after De vantier et al 2000.

\begin{tabular}{|c|c|c|c|}
\hline Taxon & Feeding Mode & Size/length [cm] & Ecological Role \\
\hline A: Wrasse (Labridae) & Carnivore & Mainly 5-15 & Mostly shalloe reef, incl. cleaner fishes \\
\hline B: Grouper (Epinephelus, Cephalopholosis) & Carnivore & $>30$ & $\begin{array}{l}\text { High level predatore, mostly solitary, hiding in big holes, habit often } \\
\text { deeper than } 5 \mathrm{~m}\end{array}$ \\
\hline C: Snapper (Lutjianidae) & Carnivore & $>30$ & High level predatore, can form small schools, hiding in holes \\
\hline D: Sweet Lip (Haemulidae) & Carnivore & $10-40$ & Low- medium level predator, small groups, hide i. a. under table corals \\
\hline E: Sugeon fish (Acanthuridae) & Herbivore & $10-30$ & Grazing/ scraping of algae, often in schools \\
\hline F: Parrot fish (Scaridae) & Herbivore/ Carnivore & $10-40$ & $\begin{array}{l}\text { Grazing/ scraping of algae and polyps from corals Some times in } \\
\text { schools, bioeroder, hide in holes during nights }\end{array}$ \\
\hline G: Butter fly fish (Chaetodontidae) & Carnivore & 7-20 & $\begin{array}{l}\text { Feed on coral polyps and sometimes on small worms etc., small to } \\
\text { large schools, hide in creef crevices during nights }\end{array}$ \\
\hline H: Rabbit fish (Siganidae) & Herbivore & $15-30$ & $\begin{array}{l}\text { Algae feeder, solitary or in small schools , live between cora;I } \\
\text { branches }\end{array}$ \\
\hline I: Sea Urchin (Echinoidea) & Herbivore & $<12$ & Important herbivorae-availability of algae \\
\hline J: Gaint Clam (Tridacna) & Mixotrophic & $<60$ & Reef building-Clam fishery \\
\hline K: Sea Cucumber (Holothurioidea) & Sediment/ detritus & $<60$ & Detritus feeder-availability of organic matter, fishery \\
\hline L: Crown-pf-Thron (Acanthaster planci) & Corallivore & $<50$ & Corollivorae-epidemics lead to great coral loss \\
\hline
\end{tabular}

Table 2: Functional groups of indicator reef fish (A-H) and invertebrates (I-L) as suggested by Reef Check (Hodgson et al. 2006). Functional groups differ in feeding mode size, habitat preferences and social behavior. (Reef Check uses most fish taxa to assess reef health and fishery impact; the indicator function for the invertebrates is mentioned in the table). 
Citation: Sawall Y, Al-Sofyani A, Kürten B, Al-Aidaroos AM, Hoang BX, et al. (2014) Coral Communities, in Contrast to Fish Communities, Maintain a High Assembly Similarity along the Large Latitudinal Gradient along the Saudi Red Sea Coast. J Ecosys Ecograph S4: 003. doi: 10.4172/2157-7625.S4-003

Page 4 of 7

other than corals, as well as fishes (fishes between bottom and surface). Here, indicator species / major taxa suggested by "Reef Check" [20] were used: non-coral invertebrates included sea urchins, giant clams, sea cucumbers and crown-of-thorn starfish, carnivore fishes included wrasses, snapper, grouper and sweetlips, the herbivore fishes contained surgeon fishes and rabbit fishes and the corallivore fishes contained parrot fishes and butterfly fishes (Table 2).

Temperature loggers (HOBO Pendant ${ }^{\oplus}$, Onset USA) were deployed at the non-polluted reefs in all regions (except Rabigh) at $3 \mathrm{~m}$ depth from February 2011 - March 2012. Water samples were collected close to the reef from $10 \mathrm{~m}$ depth in September 2011 and from 3-5 m depth in March 2012 for the analyses of chlorophyll $a(\mathrm{chl} a)$, total nitrogen (TN), total phosphorous (TP) and particulate carbon (particulate C). TN and TP concentrations for September 2011 were previously presented by Kürten [2]. All analyses were conducted using standard protocols (see supplementary information). Two seasons were chosen to capture seasonal differences in water quality.

Multivariate analyses were performed using PRIMER v6 and PERMANOVA add-on [21,22]. In order to identify trends in the assembly structure of reef communities, Principal Coordinate analyses (PCO) were conducted using the full data set. PCO, similar to Principal Component Analysis (PCA), projects samples (here sites) based on their dissimilarities on PCO axes that minimize residual variation in the space of the resemblance matrix, thereby explaining most of the variation between samples by the first view PCO axes. While PCA is based on Euclidean distance between samples, PCO allows using any distance measure. Prior to running PCO, the data was $\log _{(x+1)}{ }^{-}$ transformed down-weighing the contribution of quantitatively dominant taxa and a resemblance matrix was created based on BrayCurtis similarity.

\section{Results and Discussion}

\section{Environmental conditions}

The environmental parameters chl a, particulate $\mathrm{C}$ and $\mathrm{TP}$ concentrations, but not TN concentration, increased from north to south and were generally higher in March than in September (Figure1B), concurrent with previous descriptions of the Red Sea conditions and with satellite derived data (NASA Giovanni, Ocean Color Radiometry). This can mainly be explained by the current regime [23,24,3]: Nutrients are mainly introduced into the Red Sea from the Indian Ocean through the Bab el Mandeb and distributed towards the central Red Sea during the winter monsoon. During spring and summer, wind and surface currents are generally weaker and directed southward, while some locations in the northern Red Sea are fertilized by eddy-driven upwelling. Other nutrient sources, particularly in the northern Red Sea including the Gulf of Aqaba, are aerosols deposition and fixation of 'new nitrogen' $[2,25,26]$. We note that sampling of seawater at different depth ( 3 and $10 \mathrm{~m}$ ) in the different seasons may have introduced some bias in our seasonal comparisons, however, we are confident that the general pattern remains representative, as our nutrient related parameters can well be explained by the current regime.

Within regions, near-shore (close to sources of pollution) chl a, particulate $\mathrm{C}$ and $\mathrm{TP}$ concentrations were higher compared to the offshore sites (Figure 1B). This was particularly evident in the central Red Sea. Here, $\mathrm{RAB}^{4 \mathrm{P}}$, close to the oil refinery and cement factory, revealed 10 -fold increased values of particulate $\mathrm{C}$, and $\mathrm{JED}^{5 \mathrm{P}}$, close to a domestic waste water inlet, showed 2-fold higher concentrations of TN, when compared to their corresponding off-shore reefs (Figure1B).
Logged temperature at $3 \mathrm{~m}$ depth ranged from 21 to $27.5^{\circ} \mathrm{C}$ in the most northern region $\left(\mathrm{MAQ}^{1 \mathrm{~N}}\right)$ and from 28 to $33^{\circ} \mathrm{C}$ in the southern region $\left(\right.$ DOG $^{6 \mathrm{~N}}$ and FAR- ${ }^{7 \mathrm{~N}}$ ) (Figure 1C) from February 2011 to March 2012. The most southern region, the Farasan Islands, featured the longest continuous warm water period with temperatures above $31^{\circ} \mathrm{C}$ from May to October.

\section{Reef community assemblies along the latitudinal gradient}

Taking all investigated taxa (coral, fish and non-coral invertebrates) into consideration, the assembly structure of the reef community roughly followed a latitudinal shift, which is mainly represented by the $\mathrm{x}$-axis of the PCO (Figure 2A). This shift, however, was largely explained by the assembly structure of the coral associated community rather than by the coral community itself (Figure $2 \mathrm{~B}$ ). This suggests that the coral assemblies changed surprisingly little from north to south, despite the strong environmental gradient. Hence, corals thereby provide comparable functionality throughout the latitudinal gradient of the Red Sea. Structurally complex and fast growing Acropora species (competitive group), short branched and brooding Stylophora (weedy group) and rather bulky and slow growing species of the families Poritidae, Faviidae and Musiidae (stress-tolerant group) co-occurred throughout the gradient (Figure 2B). Only among some strategic groups, some latitudinal shifts were identified. Within the weedy group, the abundance of bushy Pocillopora (taxon 4) increased northwards. Within the competitive group, the abundance of compact bushy Acropora (taxon 1) increased northwards, while the abundance of rather long-branched and table-like Acropora (taxa 2 and 3) increased southward (Figure 2B). This demonstrates certain variability among growth forms, with more physically robust corals in the northern half of the Red Sea. The reason for this is most likely found in hydrodynamic forces, rather than in temperature or nutrient-related changes, because wave action and currents were generally stronger in the northern half than in the southern half of the Red Sea ([6] personal observation).

In contrast to the generally low stress-tolerance of Acropora species, in particular to temperature stress (Great Barrier Reef) [27,28,19], Acropora appear particularly successful throughout the Red Sea, including in the adverse warm waters conditions of the southern Red Sea. This infers specific adaptations to Red Sea conditions, which may be supported by the findings of a post-bleaching study in the northerncentral Red Sea, where certain Acropora species exhibited a strong bleaching resistance [8]. Riegl [3], likewise, described the presence of rather robust Acropora species, which mainly occur in the south, but seem to expand toward the north (e.g. A. muricata, A. nobilis). This said, the question however remains, what maintains the functionality of coral assemblies on a similar level along the Saudi Red Sea coast. Is it rather due to the adaption of single species to the entire range of environmental conditions? Or is it due to the large functional redundancy (high species richness within a functional group; [14], which allows selection for the most capable species within a given environmental setting? The second scenario may be supported after revising the differences in species richness within the strategic groups or coral taxa. Here, it was evident that large functional taxa including numerous species (e.g. 35 Acropora spp., 27 Poritidae spp., 61 Faviidae spp.) [5], barely show a north-south shift in abundance, while the smaller groups / taxa partly do. Latter was evident for the taxon Millepora within the competitive group $(<3$ species, exact number unknown), a hydrozoan genus which features a high bleaching susceptibility and was most likely therefore restricted to the northern Red Sea. Furthermore, the taxon Oculinidae within the stress-tolerant group (2 species) [5] is known for a high tolerance towards turbidity, which most likely caused a shift in abundance towards 
Citation: Sawall Y, Al-Sofyani A, Kürten B, Al-Aidaroos AM, Hoang BX, et al. (2014) Coral Communities, in Contrast to Fish Communities, Maintain a High Assembly Similarity along the Large Latitudinal Gradient along the Saudi Red Sea Coast. J Ecosys Ecograph S4: 003. doi: 10.4172/2157-7625.S4-003

Page 5 of 7
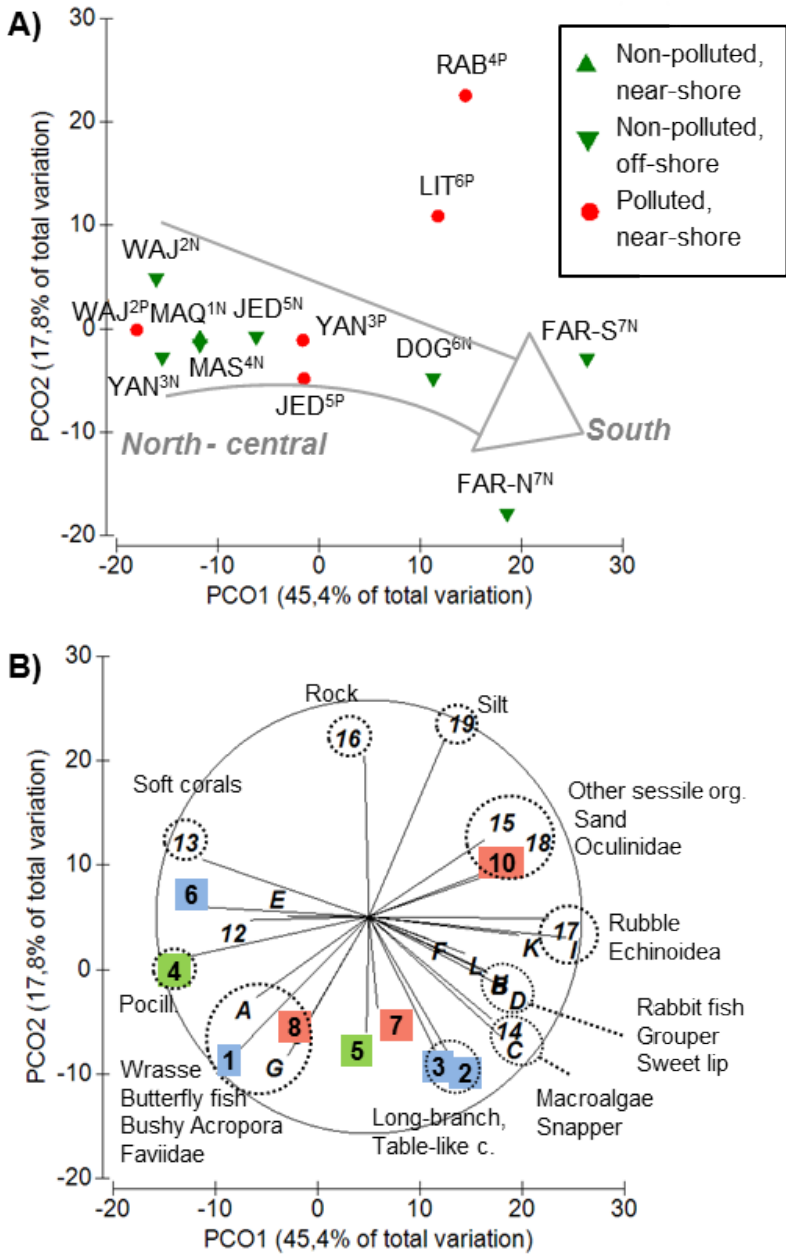

Figure 2: Results of principle coordinate analyses (PCO) for all taxa combined. A) Ordination plot representing the sites (samples) based on the dissimilarities (Bray-Curtis similarity). B) Overlying vectors of the ordination plot above. Vectors present the strength (length) and direction of the Pearson correlation of taxa with the PCO axes. All numbers and letter are explained in table 1 and 2. The colors represent the 3 large strategic groups: competitive (blue), weedy (green) and stress-tolerant (red).

near-shore and southern reefs. A last example is given by the weedy group (2 Pocillopora spp., 6 Stylophora spp.) [5], which, at least in the case of Pocillopora, seemed to be less stress-tolerant towards turbidity and high temperature, therefore occurring more in the northern Red Sea. These functional taxa, however, were generally less important for the structural complexity of reef systems and may therefore also be less important in the context of reef resilience. Thus, the latitudinal change in environmental conditions seems to be hardly reflected by the coral assembly pattern and its ecological functionality.

Not only the taxonomic and functional composition of the coral assembly, but also the composition of the non-coral substrate is important for habitat structure and functionality. Here, the coverage by rubble (0-33\%), sand (0-28\%) and macroalgae (0-5\%) increased towards the south thereby decreasing structural complexity, while the coverage by structurally supportive rock (stone and dead massive corals) was higher in the north (15-42\%) (Figure 2, Supplementary Information Table S1). Furthermore, sea urchin and sea cucumber abundance increased towards the south, where sea urchins feed on algae helping to keep algae coverage low (<5\%; see also [29,30]")", and where sea cucumbers find more nutrient-enriched sediment (e.g. sand) [29]. A decrease in soft corals towards the south is likely to be related to a decrease in water clarity $[31,32]$.

Given that habitat structure (mainly formed by the coral assembly, but also by the hard-substratum rock) is comparably high along the entire gradient, fishes should be able to find suitable habitats throughout the Saudi Red Sea coast, independent of latitude. Yet, the fish abundance and assembly structure shifted considerably from north to south (Figures 2A, 2B). Various larger fishes, the carnivore grouper, sweet lip and snapper, as well as the herbivore rabbit fish, increased in abundance towards the south (Figure 2B). This shift can mainly be ascribed to a higher nutrient input, where higher primary production and larger deposition of organic material supports the benthic food web und ultimately the larger carnivores [2]. A shift towards rather small fishes in the north, namely an increase in carnivore wrasses and corallivore butterfly fishes (Figure 2C), may have the following reasons: A lower abundance of potential predators (larger carnivores) in the north, a higher temperature sensitivity of wrasses and butterfly fishes and/or a preference for the higher energy reefs [33] as provided in the north personal observation). A limitation of our study is that we sampled fish data only in March, which may disguise potential difference in fish assemblies between seasons.

Data of percentage coverage of coral, other sessile organisms and non-living substrate (Table S1), densities of fishes and motile invertebrates (Figure S1 and S2), as well as photographs showing typical community structures at selected sites are available as Supplementary Information (Figure S3).

\section{Reef community assemblies at polluted reefs}

The reefs close to a source of pollution revealed no consistent shift in the assembly structure of reef communities, when compared to their corresponding off-shore reefs. In fact, shifts differed in direction and intensity (Figure 2A). The two most extreme situations were found in Rabigh $^{4}$ and Al-Lith ${ }^{6}$, where the variation between the non-polluted and the corresponding polluted reefs was highest. Here, the dissimilarities were mainly explained by the $y$-axis of the $\mathrm{PCO}$, indicating a general loss of coral cover, a small shift towards more massive and stress-tolerant species and an increase of non-living substrate, such as rock (mainly dead massive corals), sand and silt (Figure $2 \mathrm{~B}$ ). While at $\mathrm{RAB}^{4 \mathrm{P}}$, such indicators of reef deterioration most likely relate to the high particle load (particulate C) [34], the reason of reef deterioration at LIT ${ }^{6 \mathrm{P}}$ cannot clearly by assigned to any of the measured water parameters and might therefore be caused by other stressors. Stressors, related to the shrimp farm may include the support of harmful/toxic algae and increase abundances of chain-forming diatoms and filamentous Cyanobacteria (Trichodesmium sp.) [2], as well as the hypothetic presence of pathogens in the aquaculture effluents. Furthermore, the high abundance of coral-feeding Acanthaster plancii observed in the year prior the survey (personal observation) may have caused substantial coral loss, as well. Although some structural diversity is still maintained by the presence of rocks and dead coral boulders, habitat destruction already led to a strong reduction in fish abundance (Figure 2B).

The shift from non-polluted to polluted reefs off Yanbu ${ }^{3}$ and to a lower degree also off Jeddah ${ }^{5}$ followed the $\mathrm{x}$-axis of the PCO, i.e. these polluted near-shore reefs were more similar to the southern reefs than their corresponding non-polluted off-shore reefs (Figure 2A). This suggests that the coral assembly structure changed little, whereas higher nutrient / food supplies near-shore (indicated by increased values of 
Citation: Sawall Y, Al-Sofyani A, Kürten B, Al-Aidaroos AM, Hoang BX, et al. (2014) Coral Communities, in Contrast to Fish Communities, Maintain a High Assembly Similarity along the Large Latitudinal Gradient along the Saudi Red Sea Coast. J Ecosys Ecograph S4: 003. doi: 10.4172/2157-7625.S4-003

Page 6 of 7

nutrient-related parameters) led to higher fish abundances. Conversely, fishes seemed to be able to control for potentially increased growth of algae and other sessile organisms (low abundance, Figure $2 \mathrm{~B}$ ), which may otherwise hamper coral recruitment or coral growth $[35,11]$.

Concluding, our results show that the assembly structure of coral communities is surprisingly similar, despite strong changes in environmental conditions along the latitudinal gradient of the Saudi Red Sea coast. Complex reef habitats are formed by corals of various functional taxa, with most taxa featuring a high functional redundancy (species richness). This, together with potentially Red Sea specific adaptations of some corals, seems to maintain reef functionality throughout the gradient. In contrast, shifts in fish community assembly and abundance, as well as in non-coral invertebrates, seem to follow nutrient / food availability rather than habitat complexity. However, these fishes and non-coral invertebrates in return, control the sessile benthic community structure and reduce the abundance of potential space competitors for corals thereby maintaining coral recruitment success. In the context of global change, these results indicate that reef communities might be able to maintain its ecological functionality under predicted future scenarios, given that functional redundancy is high and changes are slow enough to allow adaptation processes. In case fast and dramatic changes occur (major nutrient increase, sedimentation, pollutants), reef functionality will be strongly compromised as it was evident at the most deteriorated reefs close to a source of pollution.

\section{Supplementary}

\section{Measurement of environmental parameter}

For chl $a, 1.51$ water sample was filtered through a GF/F filter $(0.7 \mu \mathrm{m}$, Whatman, USA) after pre-filtration through a $50 \mu \mathrm{m}$ mesh to remove the majority of zooplankton. Chl $a$ was extracted from the frozen filters with $90 \%$ acetone and determined fluorometrically (specro-fluorometer SFM 25, Kontron Instruments, Switzerland) after calibration with a spinach chl $a$ standard [36]. For particulate matter, 1.5 1 water samples were filtered through a pre-combusted GF/F filter and the filter were stored frozen. The filters were dried and the concentration of particulate C was measured with an elemental analyzer (Flash 2000, Thermo Scientific, USA, calibrated with Acetanilid). Untreated $50 \mathrm{ml}$ water samples were taken for total $\mathrm{N}(\mathrm{TN})$ and $\mathrm{P}(\mathrm{TP})$ analyses, stored in $\mathrm{PE}$-bottles and frozen until analyses. Analyses were the same as for $\mathrm{PO}_{4}$ and $\mathrm{NO}_{3}$ after all $\mathrm{P}$ and $\mathrm{N}$ was oxidized to the corresponding inorganic form as described by Grasshoff et al. [36,37,38]. Measurements were conducted with a spectra-photometer (U-2900, Hitachi High-Tech, Japan) and a $10 \mathrm{~cm}$ quartz cuvette.

\section{Acknowledgement}

This collaboration of the Jeddah Transect Project between King Abdulaziz University (KAU) and Helmholtz-Center for Ocean Research GEOMAR was founded by KAU, under grant number T-065//430-DSR. The authors therefore acknowledge with thanks KAU for technical and financial support. We also thank the Saudi and German helpers in the field, namely Salman S, Abdulrachman A and C. Lieberum, as well as the technicians at GEOMAR, S. Audritz, C. Meyer and T. Hansen. We are grateful for the reviewer's constructive comments, which improved the manuscript substantially.

\section{References}

1. Kleypas JA, McManus JW, Menez LAB (1999) Environmental limits to coral reef development: Where do we draw the line? Am Zool 39: 146-159.

2. Kürten B, Al-Aidaroos AM, Struck U, Khomayis HS, Gharbawi WY, et al. (2014) Influence of environmental gradients on $\mathrm{C}$ and $\mathrm{N}$ stable isotope ratios in coral reef biota of the Red Sea, Saudi Arabia. Journal of Sea Research 85: 379-394.

3. Raitsos DE, Pradhan Y, Brewin RJW, Stenchikov G, Hoteit I (2013) Remote sensing the phytoplankton seasonal succession of the Red Sea. PLoS ONE 8:e64909.
4. Siedler G (1969) General circulation of water masses in the Red Sea. Hot brines and recent heavy metal deposits in the Red Sea. Springer-Verlag New York, USA.

5. DeVantier L, Turak E, SI-Shaikh K, De'ath G (2000b) Coral communities of the central-northern Saudi Arabian Red Sea. Fauna of Arabia 18: 23-66.

6. Sheppard CRC, Sheppard ALS (1991) Corals and coral communities of Arabia. Fauna of Saudi Arabia 12: 3-170.

7. Riegl BM, Bruckner AW, Rowlands GP, Purkis SJ, Renaud P (2012) Red Sea coral reef trajectories over 2 decades suggest increasing community homogenization and decline in coral size. PLoS ONE 7:e38396.

8. DeVantier L, Turak E, Al-Shaikh K (2000a) Coral bleaching in the centralnorthern Saudi Arabian Red Sea, August - September 1998. International Workshop on the Extent and Impact of coral Bleaching in the Arabian Region.

9. Graham NAJ, Nash KL (2013) The importance of structural complexity in coral reef ecosystems. Coral Reefs 32: 315-326.

10. Darling ES, Alvarez-Filip L, Oliver TA, McClanahan TR, Côté IM (2012) Evaluating life-history strategies of reef corals from species traits. Ecology Letters 15: 1378-1386.

11. McClanahan TR, Sala E, Stickels PA, Cokos BA, Baker AC, et al. (2003) Interaction between nutrients and herbivory in controlling algal communities and coral condition on Glover's Reef, Belize. Mar Ecol-Prog Ser 261: 135-147.

12. Hughes TP, Rodrigues MJ, Bellwood DR, Ceccarelli D, Hoegh-Guldberg $O$, et al. (2007) Phase shifts, herbivory, and the resilience of coral reefs to climate change. Current Biology 17: 360-365.

13. Nyström M, Folke C, Moberg F (2000) Coral reef disturbance and resilience in a human-dominated environment. Trends in Ecology and Evolution 15: 413-417.

14. Bellwood DR, Hughes TP, Folke C, Nyström M (2004) Confronting coral reef crisis. Nature 429: 827-833.

15. Graham NAJ, Wilson SK, Jennings S, Polunin NVC, Bijoux JP, et al. (2006) Dynamic fragility of oceanic coral reef ecosystems. Proceedings of the National Academy of Sciences 103: 8425-8429.

16. Knowlton N (2001) The future of coral reefs. Proceedings of the National Academy of Sciences 98: 5419-5425.

17. Kotb M, Abdulaziz M, Al-Agwan Z, Al-Shaikh K, Al-Yami H, et al. (2004) Status of coral reefs in the Red Sea and Gulf of Aden in 2004. Status of coral reefs of the world: 2004. Australian Institute of Marine Science, Townsville, Queensland Australia 1: 137-154.

18. Hughes TP, Baird AH, Dinsdale EA, Moltschaniwskyj NA, Pratchett MS, et al. (2012) Assembly rules of reef corals are flexible along a steep climatic gradient Current Biology 22: 736-741.

19. Darling ES, McClanahan TR, Côté IM (2013) Life histories predict cora community disassembly under multiple stressors. Global Change Biology 19 1930-1940.

20. Hodgson G, Hill J, Kiene W, Maun L, Mihaly J, et al. (2006) Reef check instruction manual: A guide to reef check coral reef monitoring. Reef Check Foundation, Pacific Palisades, California, USA

21. Clarke KR, Gorley RN (2006) PRIMER v6: User manual, tutorial. PRIMER-E Ltd, Plymouth, England.

22. Anderson MJ, Gorley RN, Clarke KR (2008) PERMANOVA+ for PRIMER Guide to software and statistica methods. PRIMER-E Ltd, Plymouth, United Kingdom.

23. Sofianos SS, Johns WE (2003) An Oceanic General Circulation Model (OGCM) investigation of the Red Sea circulation: 2. Three-dimensional circulation in the Red Sea. J Geophys Res-Oceans 108.

24. Acker J, Leptoukh G, Shen S, Zhu T, Kempler S (2008) Remotely-sensed chlorophyll a observations of the northern Red Sea indicate seasonal variability and influence of coastal reefs. Journal of Marine Systems 69: 191-204.

25. Aberle D, Hansen T, Boettger-Schnack R, Burmeister A, Post AF, et al. (2010) Differential routing of 'new' nitrogen toward higher trophic levels within the marine food web of the Gulf of Aqaba, Northern Red Sea. Marine Biology 157: 157-169.

26. Wankel SD, Chen Y, Kendall C, Post AF, Paytan A (2010) Sources of aeroso nitrate to the Gulf of Aqaba: evidence from $\delta 15 \mathrm{~N}$ and $\delta 180$ of nitrate and trace metal chemistry. Marine Chemistry 120: 90-99. 
Citation: Sawall Y, Al-Sofyani A, Kürten B, Al-Aidaroos AM, Hoang BX, et al. (2014) Coral Communities, in Contrast to Fish Communities, Maintain a High Assembly Similarity along the Large Latitudinal Gradient along the Saudi Red Sea Coast. J Ecosys Ecograph S4: 003. doi: 10.4172/2157-7625.S4-003

27. Marshall PA, Baird AH (2000) Bleaching of corals on the Great Barrier Reef: differential susceptibilities among taxa. Coral Reefs 19: 155-163.

28. Loya, Sakai, Yamazato, Nakano, Sambali, et al. (2001) Coral bleaching: the winners and the losers. Ecology Letters 4: 122-131.

29. Uthicke S (1999) Sediment bioturbation and impact of feeding activity of Holothuria (Halodeima) atra and Stichopus chloronotus, two sediment feeding holothurians, at Lizard Island, Great Barrier Reef. B Mar Sci 64: 129-141.

30. Hughes TP, Reed DC, Boyle M-J (1987) Herbivory on coral reefs: community structure following mass mortalities of sea urchins. J Exp Mar Biol Ecol 113: 39-59.

31. Fabricius KE, McCorry D (2006) Changes in octocoral communities and benthic cover along a water quality gradient in the reefs of Hong Kong. Marine Pollution Bulletin 52: 22-33.

32. Evans A, Steer M, Belle E (2011) The Alcyonacea (soft coral and sea fans) of Antsiranana bay, northern Madagascar. Madagascar Conservation \& Development 6: 29-36.
33. Fulton C, Bellwood D, Wainwright $P$ (2001) The relationship between swimming ability and habitat use in wrasses (Labridae). Marine Biology 139: 25-33.

34. Fabricius KE (2005) Effects of terrestrial runoff on the ecology of corals and coral reefs: review and synthesis. Marine Pollution Bulletin 50: 125-146.

35. McCook LJ (1999) Macroalgae, nutrients and phase shifts on coral reefs: scientific issues and management consequences for the Great Barrier Reef Coral Reefs 18: 357-367.

36. Boto KG, Bunt JS (1978) Selective excitation fluorometry for the determination of chlorophylls and pheophytins. Analytical Chemistry 50: 392-395.

37. Grasshoff K, Ehrhardt M, Kremling K (1983) Methods of seawater analysis. Verlag Chemie Weinheim, New York, USA.

38. ICPP (2007) Climate Change 2007: Synthesis Report. An assessment of the Intergovernmental Panel on Climate Change. Cambridge University Press, Cambridge, UK.
Citation: Sawall Y, Al-Sofyani A, Kürten B, Al-Aidaroos AM, Hoang BX, et al. (2014) Coral Communities, in Contrast to Fish Communities, Maintain a High Assembly Similarity along the Large Latitudinal Gradient along the Saudi Red Sea Coast. J Ecosys Ecograph S4: 003. doi: 10.4172/2157-7625.S4-003

This article was originally published in a special issue, Marine Science handled by Editor(s). Dr. Wei Huang, University of California Riverside, USA
Submit your next manuscript and get advantages of OMICS Group submissions

\section{Unique features:}

- User friendly/feasible website-translation of your paper to 50 world's leading languages

- Audio Version of published paper

Digital articles to share and explore

Special features:

250 Open Access Journals

20,000 editorial team

21 days rapid review process

Quality and quick editorial, review and publication processing

Indexing at PubMed (partial), Scopus, EBSCO, Index Copernicus and Google Scholar etc

Sharing Option: Social Networking Enabled

- Authors, Reviewers and Editors rewarded with online Scientific Credits

Better discount for your subsequent articles

Submit your manuscript at: http://www.omicsonline.org/submission 